\title{
Evaluasi Hasil Pembelajaran Melalui Penggunaan Media Pembelajaran Microsoft Power Point
}

\author{
Erlin Marlina ${ }^{1 凶}$, Syarwani Ahmad ${ }^{2}$, Syaiful Eddy ${ }^{3}$ \\ (1) Sekolah Dasar Negeri 1 Gardu Harapan \\ $(2,3)$ Universitas PGRI Palembang
}

$\square$ Corresponding author

[erlinkuliah@gmail.com]

\begin{abstract}
Abstrak
Penelitian ini bertujuan untuk (1) mengetahui tahapan proses pengembangan media pembelajaran dengan menggunakan media Power Point pada mata pelajaran IImu Pengetahuan Alam; (2) meningkatkan hasil belajar siswa melalui media Power Point; (3) mengetahui cara membuat media pembelajaran Power Point menjadi menarik. Jenis penelitian yang digunakan dalam penelitian ini adalah penelitian dan pengembangan atau Research and Development (R\&D). Objek dalam penelitian ini adalah media pembelajaran berbasis TIK Power Point Interaktif pada mata pelajaran IImu Pengetahuan Alam (IPA) materi gaya. Subjek dalam penelitian ini adalah siswa kelas V SD Negeri 1 Gardu Harapan. Prosedur pengembangan produk yang dilakukan peneliti melalui media pembelajaran menggunakan media Power Point dalam pelajaran IImu Pengetahuan Alam (IPA) dengan materi gaya. Prosedur pengembangan menggunakan Research and Devlopment (R\&D) teori dari Bord and Gall dengan 10 langkah pengembangan produk, yaitu Analisis Kebutuhan dengan mengungkapkan Potensi dan Masalah, Pengumpulan Data, Desain Produk, Validasi Desain, Revisi Desain, Uji Coba Produk, Revisi Produk, Uji Coba Pemakaian, Revisi Produk, dan Produk Masal.
\end{abstract}

Kata Kunci: Pengembangan Media Pembelajaran; Power Point; Pembelajaran IPA.

\begin{abstract}
This study aims to (1) Determine the stages of the development process of learning media using Power Point media in Natural Sciences; (2) improving student learning outcomes through Power Point media; (3) knowing how to make Power Point learning media interesting. This type of research used in this research is research and development. The object of this research is ICT-based Interactive Power Point learning media on the subject of Natural Sciences (IPA) style material. The subjects in this study were fifth grade students of SD Negeri 1 Gardu Harapan. Product development procedures conducted by researchers through learning media using Power Point media in Natural Sciences (IPA) lessons with style material. The development procedure uses the Research and Development (R\&D) theory from Bord and Gall with 10 steps of product development, namely Analysis of Needs by revealing Potential and Problems, Data Collection, Product Design, Design Validation, Design Revision, Product Trial, Product Revision, Trial Use, Product Revision and Mass Products.
\end{abstract}

\section{Keyword: Development of Learning Media; Power Point; Science Learning}

\section{PENDAHULUAN}

Pendidikan adalah salah satu perwujudan kebudayaan manusia yang dinamis dan merupakan syarat meningkatkan mutu pendidikan (Listiningrum dkk, 2020). Oleh karena itu, perubahan atau peningkatan pendidikan adalah hal yang memang seharusnya terjadi sejalan dengan perubahan budaya kehidupan. Perubahan dalam arti perbaikan pendidikan pada semua jenjang pendidikan perlu terus-menerus dilakukan sebagai antisipasi kepentingan masa depan. Seperti yang tercantum pada Undang-Undang nomor 20 tahun 2003 tentang Sistem Pendidikan Nasional yang menyatakan bahwa Pendidikan Nasional berfungsi meningkatkan kemampuan dan membentuk watak serta peradaban bangsa yang bermartabat dalam rangka mencerdaskan kehidupan bangsa (Soleh dkk, 2019; Septiani dan Cahyono, 2019).

Salah satu kegiatan pokok yang dilakukan oleh guru dalam proses pembelajaran di kelas adalah mengajar. Mengajar adalah mengorganisasi hal-hal yang berhubungan dengan belajar. Salah satu hal utama dalam pelaksanaan kegiatan mengajar adalah kompetensi guru sebagai pelaksana kegiatan mengajar. Pelaksanaan kegiatan mengajar yang baik, terarah dan terencana dapat mencapai tujuan pembelajaran, untuk itulah kompetensi guru sangat dibutuhkan. Kompetensi guru sebagaimana yang dimaksud dalam pasal 8 Undang-Undang Republik Indonesia Nomor 14 tahun 2005 meliputi kompetensi pedagogik, kompetensi kepribadian, kompetensi sosial, dan kompetensi profesional yang diperoleh melalui pendidikan profesi, yang 
apabila dijabarkan termasuk kemampuan untuk memilih media pembelajaran yang tepat dan dapat dipahami oleh peserta didik (Zulaiha dkk, 2020; Darmiati dkk, 2020; Nugraha, 2019).

Kompetensi pedagogik merupakan salah satu jenis kompetensi yang mutlak perlu dikuasai guru. Hal ini dikarenakan melalui kompetensi pedagogik guru tersebut maka proses pembelajaran dan pengelolaan peserta didik dapat dilakukan dengan baik dan terencana yang pada akhirnya dapat meningkatkan kualitas pembelajaran. Lebih jauh kompetensi pedagogik menurut Badan Standar Nasional Pendidikan (BSNP) adalah kemampuan dalam pengelolaan peserta didik dan materi ajar serta media pembelajaran, sehingga proses pembelajaran dapat berlangsung dengan baik (Komalasari dkk, 2020).

Berdasarkan pendapat-pendapat di atas, dapat disimpulkan bahwa kemampuan menggunakan alat yang tepat dalam mengelola pembelajaran yang baik dapat meningkatkan hasil belajar yang baik. Kemampuan guru itu sendiri berhubungan langsung dengan kegiatan belajar mengajar yang pada akhirnya akan mempengaruhi hasil (prestasi) belajar siswa. Hal ini sesuai dengan pendapat Daryanto (2010) bahwa proses belajar mengajar dan hasil dan prestasi belajar yang diperoleh siswa tidak hanya ditentukan oleh sekolah, pola struktur dan isi kurikulumnya, tetapi ditentukan juga oleh kemampuan guru yang mengajar dan bimbingan terhadap siswa (Fitria dan Suminah, 2020).

Jelaslah bahwa pendidikan merupakan investasi jangka panjang yang memerlukan usaha dan dana yang cukup besar, hal ini diakui oleh hampir semua masyarakat suatu bangsa dimanapun demi kelangsungan masa depannya. Demikiannya dengan Indonesia menaruh harapan besar terhadap pendidik (Guru) dalam meningkatkan mutu masa depan pendidikan di Indonesia (Kartini dkk, 2020; Mukartik dkk, 2020; Rohma dkk, 2020).

Daryanto (2013) mengemukakan bahwa pendidikan adalah proses sengaja untuk meneruskan atau mentransmisi budaya orang dewasa kepada generasi yang lebih muda. Sedangkan menurut Undang-Undang Republik Indonesia Nomor 20 tahun 2003 tentang Sistim Pendidikan Nasional menyebutkan "Pendidikan adalah usaha sadar dan terencana untuk mewujudkan suasana belajar dan proses pembelajaran agar peserta didik secara aktif meningkatkan potensi dirinya untuk memiliki kekuatan spiritual keagamaan, pengendalian diri, kepribadian, kecerdasan, aklak mulia, serta ketrampilan yang dibutuhkan bagi dirinya, masyarakat dan bangsa". Pendidikan merupakan pendewasaan peserta didik agar dapat meningkatkan bakat, potensi dan ketrampilan yang dimiliki dalam menjalani kehidupan, oleh karena itu sudah seharusnya pendidikan didesain guna memberikan pemahaman serta meningkatkan prestasi belajar peserta didik (Abdullah, 2020; Hartiwi dkk, 2020; Apriani dkk, 2020).

\section{METODE PENELITIAN}

Jenis penelitian yang digunakan dalam penelitian ini adalah penelitian kualitatif. Sugiyono (2018) menyatakan bahwa penelitian kualitatif adalah metode penelitian yang berlandaskan para filsafat postpositivisme, digunakan untuk meneliti pada kondisi objek yang ilmiah, sebagai lawannya adalah eksperimen) dimana secara triaguler (gabungan), analisis data bersifat kualitatif dan hasil penelitian.

Pendekatan kualitatif dalam penelitian ini bersifat deskriftif. Proses yang dilakukan adalah pengumpulan data serta menganalisis dan penafsiran data tersebut. Pada hakekatnya penelitian deskriftif kualitatif adalah suatu metode dalam meneliti status sekelompok manusia, suatu objek dengan tujuan membuat deskriftif, gambaran atau lukisan secara sistematis, dan faktual dan akurat mengenai fakta-fakta atau fenomena yang diselidiki. Metode penelitian yang digunakan untuk mengevaluasi hasil pembelajaran melalui penggunaan media media Power Point pada mata pelajaran IImu Pengetahuan Alam (IPA) dengan materi gaya di kelas V SD Negeri 1 Gardu Harapan, akan mengungkapkan hasil secara nyata yang diperoleh antara kelas kontrol dengan kelas eksperimen.

Teknik pengumpulan data dalam penelitian terdiri dari wawancara, observasi dan dokumentasi. Wawancara merupakan teknik pengumpulan data yang dilakukan peneliti melalui percakapan dan tanya jawab, biak langsung maupun tidak langsung. Wawancara juga merupakan percakapan dengan maksud tertentu. Sehingga wawancara merupakan suatu percakapan antara penanya dan nara sumber dengan tanya jawab baik secara langsung maupun tidak langsung dengan tujuan tertentu.

Pada penelitian ini, peneliti mengambil bentuk pertanyaan wawancara mendalam/ terbuka (open/ended) yaitu pertanyaan yang bersifat terbuka dimana partisifan secara bebas menjawab pertanyaan tersebut dan peneliti bisa mengambil data yang lebih detil dan rinci dengan tetap memperhatikan pedoman wawancara. Pada penelitian ini peneliti melakukan wawancara pra penelitian terhadap guru A mengenai analisis kebutuhan. Tujuan penelitian melakukan wawancara untuk menemukan permasalahan berbasis TIK pada media pembelajaran Power Point di kelas V SD Negeri 1 Gardu Harapan.

Wawancara ini bertujuan untuk mendapatkan berbagai jawaban secara langsung dari para informan sebagai bahan penulisan penelitian. Sedangkan dalam hal ini yang menjadi informan adalah guru dan siswa. Metode wawancara ini bertujuan untuk mendapatkan berbagai informasi tentang hasil pembelajaran sebelum dan sesudah menggunakan media powerpoint. 
Wawancara yang dilakukan peneliti menggunakan pertanyaan-pertanyaan. Pertanyaan ini akan dijabarkan peneliti pada instrumen penelitian. Pertanyaan wawancara dilakukan kepada guru kelas $V$ SD Negeri 1 Gardu Harapan mengenai penerapan media pembelajaran menggunakan media Power Point pada pelajaran IImu Pengetahuan Alam (IPA) materi pelajaran tentang gaya.

Observasi merupakan bagian yang terpenting dalam penelitian kualitatif. Observasi merupakan aktifitas pencatatan fenomena yang dilakukan secara sistematis. Dengan observasi, peneliti dapat mendokumentasikan dan merefleksi secara sistematis terhadap kegiatan dan interaksi subjek penelitian. Semua yang dilihat dan didengar sesuai dengan tema penelitian, semua fleksibel dicatat dalam kegiatan observasi yang terencana secara fleksibel dan terbuka.

Observai ialah pemilihan, pengubahan, pencatatan dan penggodean serangkaian perlaku dengan suasana yang berkenaan dengan organisasi, sesuai dengan tujuan-tujuan empiris. Dilihat dari segi proses pelaksanaan pengumpulan data, observasi dapat dibedakan menjadi (particiipant observation) observasi berperan serta partipant observation. Maka dalam hal ini penulis menggunakan jenis observasi berperan serta, karna observasi ini peneliti terlibat dalam kegiatan yang sedang diamati yang digunakan sebagai sumber data penelitian. Metode observasi ini digunakan dengan tujuan untuk memperoleh gambaran secara menyeluruh mengenai evaluasi hasil pembelajaran melalui pengunaan media pembelajaran microsoft powerpoint di SD Negeri 1 Gardu Harapan Kecamatan Lais Kabupaten Musi Banyuasin.

Dokumentasi merupakan catatan peristiwa yang sudah berlalu. Dokumentasi bisa berbentuk tulisan, gambar atau karya-karya monumental dari seseorang. Hasil penelitian dari wawancara dan observasi akan lebih kredibel/dapat dipercaya bila didukung oleh dokumentasi.

Dari ketiga metode diatas yaitu metode wawancara, observasi serta dokumentasi akan digunakan metode yang saling melengkapi antaranya satu dengan yang lainnya dengan tujuan dapat mempermudah penulis untuk mendapatkan data-data yang dibutuhkan dalam penelitian.

Pada tahapan dalam analisis data dalam proses analisis data kualitatif terdapat tiga kegiatan utama yang terjadi secara bersamaan dan saling berkaitan yaitu reuksi data, penyajian data dan penarikan kesmpulan atau verifikasi.

Reduksi data adalahproses pemilihan, pemusatan perhatian pada penyederhanaaan, pengabstrakan, dan transformasi data kasar yang muncul dilapangan. Selain itu reduksi data digunakan untuk menajamkan, menggolongkan, mengarahkan, membuang yang tidak perlu dan mengorganisir data dengan cara yang sedemikian rupa sehingga kesimpulan-kesimpulan finalnya dapat ditarik dan diverivikasi.

Penyajian data merupakan analisis dalam bentuk matrik, network, cart, atau grafis. Pada penelitian kualitatif, penyajian data dilakukan dalam bentuk uraian singkat, tabel, bagan dan hubungan antar kategori. Melalui penyajian data tersebut, maka data terorganisasikan, dan tersusun sehingga akan semakin mudah dipahami. Penyajian data (Display Data) dibuat guna memudahkan peneliti dalam melihat keseluruhan data hasil wawancara atau melihat bagian khusus dari hasil wawancara. Yang dimaksud dengan wawancara adalah proses memperoleh keterangan untuk tujuan penelitian dengan cara tanya jawab, sambil bertatap muka antara yang ditanya dengan si penanya dengan menggunakan alat yang dinamakan interview guide (panduan wawancara).

Dalam penelitian ini, penyajian dta disusun dalam bentuk teks naratif (kumpuylan kalimat) yang dirancang guna menggabungkan informasi yang tersusun dalam suatu bentuk yang mudah dibaca atua diinterprestasikan. Dengan cara ini peneliti dapat melihat apa yang sedang terjadi dan dapat menarik kesimpulan secara tepat.

Data kualitatif yang dikembangkan oleh milles dan Hunbermanbahwa penarikan kesimpulan dan verivikasi. Kesimpulan awal yang dikemukakan masih bersifat sementara, dan akan berubah apabila tidak ditemukan bukti-bukti kuat yang mendukung tahap pengumpulan berikutnya. Kesimpulan dalam penelitian kualitatif dapat menjawab rumusan masalah yang dirumuskan sejak awal.

Penarikan kesimpulan dilakukan secara terus-menerus sepanjang proses penelitian, dan verifikasi dilakukan guna perbaikan dan pencocokan data secara terus-menerus selam proses penelitian berlangsung. Setiap pengambilan kesimpulan senantiasa terus-menerus dilakukan verifikasi selama penelitian berlangsung.

\section{HASIL DAN PEMBAHASAN}

Penerapan di Kelas Kontrol

Hasil penelitian yang diteliti pada 20 orang siswa dengan jumlah soal sebanyak 20 soal, dapat dilihat pada tabel 1. Berdasarkan data pada tabel 1, nilai pretest dari 25 siswa dengan nilai tertinggi adalah 68, dan nilai terendah adalah 23, sedangkan nilai rata-rata 36,44. KKM mata pelajaran IImu Pengetahuan Alam adalah 80,00 . Hasil penelitian yang diteliti pada 20 orang siswa pada kelas kontrol Posttest dengan jumlah soal sebanyak 20 soal, dapat dilihat pada tabel 2. Berdasarkan data pada tabel 2, nilai posttest dari 20 siswa dengan nilai tertinggi adalah 69, dan nilai terendah adalah 24, sedangkan nilai rata-rata 37,56. KKM mata pelajaran IImu Pengetahuan Alam adalah 80,00. Kelas kontrol adalah kelas yang tidak diajar menggunakan media pembelajaran yang baru. Kelas kontrol pada penelitian ini adalah kelas IV SD Negeri 1 Gardu Harapan. Kelas 
IV ini masih menggunakan media pembelajaran dengan model ceramah, media yang disediakan berupa buku dan papan tulis. Kegiatan yang dilakukan pada saat pertama kali pertemuan dengan melakukan pretest. Tujuan dilakukan pretest ini untuk mengetahui keadaan siswa pada awal pertama kali pembelajaran. Guru mengajar menggunakan metode ceramah. Setelah selesai guru membagikan soal posttest kepada siswa. Untuk mengetahui nilai hasil pretest dan posttest dapat dilihat pada daftar lampiran. Sedangkan hasil perbandingan nilai pretest dan posttest dapat dilihat pada tabel 3. Pada tabel 3, terjadi peningkatan antara pretest dan posttest. Namun peningkatan hanya sedikit sekali. Nilai terendah pada saat pretest adalah 23 dan nilai terendah pada saat posttest adalah 24 . Hasil tes ini terjadi peningkatan hanya sedikit. Nilai tertinggi pada saat pretest adalah 68 dan nilai tertinggi pada saat posttest adalah 69 Penilaian ini juga mengalami peningkatan. Nilai KKM sebesar 80,00. Rata-rata nilai pretest adalah sebesar 36,44 atau 45,55\% dan posttest adalah sebesar 37,56 atau $47,08 \%$.

Tabel 1. Hasil Penelitian Penerapan Media Pembelajaran Power Point SD Negeri 1 Gardu Harapan

\begin{tabular}{llllllllll}
\hline No & $\begin{array}{l}\text { Jumlah } \\
\text { Nilai }\end{array}$ & No Jumlah & No & $\begin{array}{l}\text { Jumlah } \\
\text { Nilai }\end{array}$ & No & $\begin{array}{l}\text { Jumlah } \\
\text { Nilai }\end{array}$ & No & $\begin{array}{l}\text { Jumlah } \\
\text { Nilai }\end{array}$ \\
\hline $\mathbf{1}$ & 32 & 6 & 51 & 11 & 23 & 16 & 43 & 21 & 29 \\
\hline $\mathbf{2}$ & 49 & 7 & 30 & 12 & 23 & 17 & 52 & 22 & 23 \\
\hline $\mathbf{3}$ & 39 & 8 & 68 & 13 & 23 & 18 & 23 & 23 & 23 \\
\hline $\mathbf{4}$ & 53 & 9 & 24 & 14 & 23 & 19 & 60 & 24 & 40 \\
\hline $\mathbf{5}$ & 51 & 10 & 23 & 15 & 23 & 20 & 60 & 25 & 23 \\
\hline
\end{tabular}

Tabel 2. Hasil Penelitian Penerapan Media Pembelajaran Power Point SD Negeri 1 Gardu Harapan

\begin{tabular}{llllllllll}
\hline No & $\begin{array}{l}\text { Jumlah } \\
\text { Nilai }\end{array}$ & No & $\begin{array}{l}\text { Jumlah } \\
\text { Nilai }\end{array}$ & No & $\begin{array}{l}\text { Jumlah } \\
\text { Nilai }\end{array}$ & No & $\begin{array}{l}\text { Jumlah } \\
\text { Nilai }\end{array}$ & No & $\begin{array}{l}\text { Jumlah } \\
\text { Nilai }\end{array}$ \\
\hline $\mathbf{1}$ & 34 & 6 & 52 & 11 & 24 & 16 & 44 & 21 & 31 \\
\hline $\mathbf{2}$ & 50 & 7 & 31 & 12 & 24 & 17 & 52 & 22 & 25 \\
\hline $\mathbf{3}$ & 39 & 8 & 69 & 13 & 24 & 18 & 24 & 23 & 24 \\
\hline $\mathbf{4}$ & 52 & 9 & 26 & 14 & 24 & 19 & 61 & 24 & 42 \\
\hline $\mathbf{5}$ & 52 & 10 & 24 & 15 & 24 & 20 & 62 & 25 & 25 \\
\hline
\end{tabular}

Tabel 3. Hasil Perbandingan Nilai Pretest dan Posttest Siswa Kelas IV SD dan Kelas V SD Negeri 1 Gardu Harapan

\begin{tabular}{llll}
\hline No & Nilai & Pretest & Posttest \\
\hline $\mathbf{1}$ & Nilai Terendah & 68 & 69 \\
\hline $\mathbf{2}$ & Nilai Tertinggi & 23 & 24 \\
\hline $\mathbf{3}$ & Rata-Rata & 36,44 & 37,56 \\
\hline
\end{tabular}

\section{Penerapan di Kelas Eksperimen}

Kelas eksperimen adalah kelas yang diajarkan dengan menggunakan media pembelajaran Power Point. Kelas yang dipilih sebagai kelas eksperimen adalah kelas V SD Negeri 1 Gardu Harapan. Alat pendukung pembelajaran adalah buku, papan tulis, infokus, dan komputer. Kegiatan pembelajaran pada kelas eksperimen adalah pada awal pembelajaran siswa diberikan soal pretest yang sudah disediakan. Siswa mengisi angket. Setelah selesai mengerjakan soal pretest siswa menerima materi pelajaran gaya menggunakan media pembelajaran Power Point. Setelah guru menyampaikan materi dan dilakukan tanya jawab kepada siswa, siswa diberikan soal posttest. Hasil penelitian yang diteliti pada 30 orang siswa dengan jumlah soal sebanyak 20 soal, dapat dilihat pada tabel 4.

Tabel 4. Hasil Penelitian Penerapan Media Pembelajaran Power Point SD Negeri 1 Gardu Harapan

\begin{tabular}{llllllllllll}
\hline No & $\begin{array}{l}\text { Jumlah } \\
\text { Nilai }\end{array}$ & No & $\begin{array}{l}\text { Jumlah } \\
\text { Nilai }\end{array}$ & No & $\begin{array}{l}\text { Jumlah } \\
\text { Nilai }\end{array}$ & No & $\begin{array}{l}\text { Jumlah } \\
\text { Nilai }\end{array}$ & No & $\begin{array}{l}\text { Jumlah } \\
\text { Nilai }\end{array}$ & No & $\begin{array}{l}\text { Jumlah } \\
\text { Nilai }\end{array}$ \\
\hline $\mathbf{1}$ & 35 & 6 & 54 & 11 & 34 & 16 & 61 & 21 & 55 & 26 & 33 \\
\hline $\mathbf{2}$ & 47 & 7 & 78 & 12 & 43 & 17 & 61 & 22 & 61 & 27 & 32 \\
\hline $\mathbf{3}$ & 38 & 8 & 71 & 13 & 31 & 18 & 26 & 23 & 51 & 28 & 42 \\
\hline $\mathbf{4}$ & 63 & 9 & 31 & 14 & 32 & 19 & 70 & 24 & 60 & 29 & 42 \\
\hline $\mathbf{5}$ & 50 & 10 & 32 & 15 & 59 & 20 & 60 & 25 & 41 & 30 & 60 \\
\hline
\end{tabular}


Berdasarkan data pada tabel 4, nilai pretest dari 30 siswa dengan nilai tertinggi adalah 78, dan nilai terendah adalah 26 , sedangkan nilai rata-rata 49,80. KKM mata pelajaran IImu Pengetahuan Alam adalah 80,00 .

Sedangkan Hasil penelitian yang diteliti pada 30 orang siswa pada kelas eksperimen. Posttest dengan jumlah soal sebanyak 20 soal, dapat dilihat pada tabel 5. Berdasarkan data pada tabel 5, nilai posttest dari 30 siswa dengan nilai tertinggi adalah 80 , dan nilai terendah adalah 60, sedangkan nilai rata-rata 67,87. KKM mata pelajaran IImu Pengetahuan Alam adalah 80,00.

Data hasil pretest dan posttest pada kelas kontrol dan kelas ekperimen, dapat dilihat perbandingan nilai pretest dan posttest materi pelajaran gaya pada mata pelajaran Ilmu Pengetahuan Alam menggunakan media pembelajaran Power Point pada tabel 6.

Tabel 5. Hasil Penelitian Penerapan Media Pembelajaran Power Point SD Negeri 1 Gardu Harapan

\begin{tabular}{lllllllll}
\hline $\begin{array}{l}\text { Jumlah } \\
\text { Nilai }\end{array}$ & No & $\begin{array}{l}\text { Jumlah } \\
\text { Nilai }\end{array}$ & No & $\begin{array}{l}\text { Jumlah } \\
\text { Nilai }\end{array}$ & No & $\begin{array}{l}\text { Jumlah } \\
\text { Nilai }\end{array}$ & No & $\begin{array}{l}\text { Jumlah } \\
\text { Nilai }\end{array}$ \\
\hline 71 & 11 & 67 & 16 & 61 & 21 & 62 & 26 & 66 \\
\hline 80 & 12 & 68 & 17 & 61 & 22 & 61 & 27 & 71 \\
\hline 71 & 13 & 69 & 18 & 63 & 23 & 65 & 28 & 66 \\
\hline 60 & 14 & 68 & 19 & 70 & 24 & 62 & 29 & 63 \\
\hline 67 & 15 & 71 & 20 & 63 & 25 & 80 & 30 & 73 \\
\hline
\end{tabular}

Tabel 6. Hasil Perbandingan Nilai Pretest dan Postes Siswa Kelas V SD Negeri 1 Gardu Harapan

\begin{tabular}{llll}
\hline No & Nilai & Pretest & Posttest \\
\hline $\mathbf{1}$ & Nilai Terendah & 26 & 60 \\
\hline $\mathbf{2}$ & Nilai Tertinggi & 78 & 80 \\
\hline 3 & Rata-Rata & 49,80 & 67,87 \\
\hline
\end{tabular}

\section{SIMPULAN}

Hasil belajar siswa melalui media Power Point di SD Negeri 1 Gardu Harapan pada saat dilakukan penelitian di kelas kontrol masih rendah, karena guru masih menjelaskan dengan metode ceramah. Setelah dilakukan penelitian di kelas eksperimen, hasil belajar siswa mengalami peningkatan. Hal ini dikarenakan guru menggunakan media pembelajaran Power Point. Nilai tertinggi di kelas kontrol pada saat prestest adalah 68 dan nilai terendah adalah 23, sedangkan rata-rata nilai siswa diperoleh sebesar 36, 44 atau 45,55\%. Nilai tertinggi di kelas kontrol pada saat posttest adalah 69, nilai terendah adalah 24 dan rata-rata nilai siswa di peroleh sebesar 37,56 atau $46,95 \%$. Nilai siswa pada kelas eksperimen mengalami peningkatan, pada saat dilakukan pretest nilai tertinggi adalah 78, nilai terendah adalah 26 dan rata-rata nilai siswa diperoleh sebesar 49,80 atau sebesar 62,25\%. Nilai siswa di kelas eksperimen pada saat dilakukan posttest dengan nilai tertinggi adalah 80, nilai terendah adalah 60 dan rata-rata nilai diperoleh sebesar 67,87 atau 84,84\%.

\section{UCAPAN TERIMA KASIH}

Terima kasih penulis ucapkan kepada kepadla sekolah dan guru Sekolah Dasar Negeri 1 Gardu Harapan dan semua pihak yang telah membantu selesainya penelitian ini.

\section{DAFTAR PUSTAKA}

Abdullah, A. (2020). Relationship the Work Culture and Training Programs Within Performance. International Journal of Progressive Sciences and Technologies (IJPSAT), 20(1).

Apriani, N., Fatonah, F., \& Oka, I. A. M. (2020). Rancangan Sistem Pengolahan Sertifikat Berbasis Website Sebagai Upaya Untuk Peningkatan Evaluasi Kompetensi Safety Personil Di Lingkungan PT Angkasa Pura II (Persero). Langit Biru: Jurnal IImiah Aviasi, 17-28.

Darmiati, D., Kristiawan, M., \& Rohana, R. (2020). The Influence of School Leadership and Work Motivation toward Teacher's Discipline. Journal of Social Work and Science Education, 1(1), 32-44.

Daryanto. (2010). Media Pembelajaran. Bandung: Satu Nusa

Daryanto. (2013). Administrasi dan Manajemen Sekolah. Jakarta: PT Asdi Mahasatya.

Fitria, H., \& Suminah, S. (2020). Role of Teachers in Digital Instructional Era. Journal of Social Work and Science Education, 1(1), 70-77.

Hamzah, S., Yussof, M. H. B., \& Enriquez, A. A. (2020). Togetherness in the Diversity of the Pancasila Ideology Frame. Journal of Social Work and Science Education, 1(1), 8-12. 
Hartiwi, H., Kozlova, A. Y., \& Masitoh, F. (2020). The Effect of Certified Teachers and Principal Leadership toward Teachers' Performance. International Journal of Educational Review, 2(1), 70-88.

Komalasari, K., Arafat, Y., \& Mulyadi, M. (2020). Principal's Management Competencies in Improving the Quality of Education. Journal of Social Work and Science Education, 1(2), 181-193.

Listiningrum, H. D., Wisetsri, W., \& Boussanlegue, T. C. H. A. B. L. E. (2020). Principal's Entrepreneurship Competence in Improving Teacher's Entrepreneurial Skill in High Schools. Journal of Social Work and Science Education, 1(1), 87-95.

Murkatik, K., Harapan, E., \& Wardiah, D. (2020). The Influence of Professional and Pedagogic Competence on Teacher's Performance. Journal of Social Work and Science Education, 1(1), 58-69.

Nugraha, W. (2019) Safety Documentation: A Communication Approach For Safety Management System In Aerodrome Operator. International Journal of Scientific \& Technology Research 8 (11), 1705-1711

Rohma, S., Harapan, E., \& Wardiah, D. (2020). The Influence of School-Based Management and Teacher's Professionalism toward Teacher's Performance. Journal of Social Work and Science Education, 1(1), 13-23.

Septiani, V., \& Cahyono, D. (2019). Education and Training Strategy in Palembang Aviation College. International Journal of Recent Technology and Engineering, 8 (3)

Soleh, A. M., Tobari., Kesumawati, N. (2019). Development of The Practical Manual As A Learning Media For Simulator Aircraft Rescue And Fire Fighting. International Journal of Scientific \& Technology Research 8(10).

Sugiyono. (2018). Metode Penelitian Kuantatif, Kualitatif dan R\&D. Bandung: Alfabeta.

Undang-Undang Republik Indonesia Nomor 20 tahun 2003

Zulaiha, D., Lian, B., \& Mulyadi, M. (2020). The Effect of Principal's Competence and Community Participation on the Quality of Educational Services. Journal of Social Work and Science Education, 1(1), 45-57. 